\title{
COVID-19 Vaccine: A Global Race
}

\author{
KAMEL EARAR ${ }^{1}$, VANIA ATUDOREI ${ }^{2 *}$, ISTEQLAL SAMI NAZMI MAHMOUD², \\ MANUELA ARBUNE ${ }^{1 *}$, VALERIU ROMULUS HARABOR ${ }^{1}$, OVIDIU SCHIPOR ${ }^{1}$, \\ ANA MAGDALENA BRATU ${ }^{3}$, CRISTINA SERBAN ${ }^{1}$, SERBAN DRAGOSLOVEANU ${ }^{3}$, \\ SILVIA FOTEA ${ }^{1}$, AUREL NECHITA ${ }^{1}$ \\ 1"Dunarea de Jos" University, Medicine \& Pharmacy Faculty, 47 Domneasca Str., 800008, Galati, Romania \\ ${ }^{2}$ Laval University, Faculty of Pharmacy, Quebec, Canada \\ ${ }^{3}$ Carol Davila University of Medicine and Pharmacy, Departament of Radiology and Medical Imaging, Coltea Clinical \\ Hospital, 1 Ion C. Bratianu Av., 030171, Bucharest, Romania
}

\begin{abstract}
The emergence of the new coronavirus SARS-CoV-2, at the end of 2019, triggered the worst pandemic of the last century, called COVID-19. Unlike SARS-CoV-1, which developed as an epidemic in 1996 but was limited to Asia, the new SARS -CoV-2 spread rapidly to millions of people worldwide, with a high mortality rate. Deciphering the structure of the viral S and SARS-CoV genome-2 allowed the identification of targets for vaccination, the most important being the viral protein $S$. The development of-COVID-19vaccines is based on use innovative biotechnologies, some even experimental. Experience in vaccines SARS-CoV-1-MERS-CoV and may be useful for designing bad vaccine by emerging virus of SARS-CoV-2. Developing a vaccine anti-COVID-19 efficient, safe and accessible in the shortest possible time, remains the biggest challenge overall, in the race to limit pandemic today.
\end{abstract}

Keywords: vaccine, COVID-19, coronavirus, S protein

\section{Introduction}

The emergence of the new SARS-CoV-2 coronavirus, at the end of 2019, triggered the worst pandemic of the last century, called COVID-19. In SARS-CoV contrast to one that evolved epidemic in 1996, but was limited to the territory of Asia, new SARS-CoV-2 spread rapidly to millions of persons worldwide. The first epidemiological reports in China indicated a predominance of mild and moderate forms, with a share of $20 \%$ of severe forms and a mortality rate of $1-3 \%$ [1].

By present, one can not find a drug with antiviral efficacy is proven, although many molecules that have been studied for the treatment of the torus infections, are used in various clinical trial are patients with COVID-19, for example, remdesivir or lopinavir / ritonavir. For the time being, infection prevention is based on social segregation measures, the use of protective masks and oral hygiene, but the best way to control the spread of the disease is to be expected from vaccination immunization. That is why that interest for development of an effective vaccine for SARS-CoV-2 is a priority for research, but also for clinical medicine and pharmaceutical industry.

The World Health Organization provides technical support for mobilizing re-sources and crisis generated by the pandemic COVID-19, in a difficult period, political instability and serious economic recession. This vaccine is stained as a lifesaving procedure, but achieving safe vaccines, efficient and affordable worldwide is the biggest challenge of the moment.

\section{Materials and methods}

Paper aims to synthesize and present information on developing vaccins anti-COVID-19.

The study type review was based on the analysis of the dates or published in medical literature database WEB OF SCIENCE, during December 2019 - Mai 2020.

*email: microbiology@sympatico.ca, manuela.arbune@ugal.ro 


\section{Results and discussions}

\section{Structural shift and viral replication circle for coronaviruses}

SARS-CoV-2 is part of the Coronaviridae, so-named because the appearance of the crown given by the viral surface glycoproteins, observed under the electronic microscope. Coronaviruses are divided into two subfamilies, Letovirinae and Orthocoronavirinae, the latter having four genera: Alpha-, Betha-, Gamma- and Delta-coronaviruses. SARS-CoV-2 is part of the genus Bethacoronavirus, along with SARS-CoV-1 and MERS-CoV. The association of coronaviruses with mild respiratory infections has long been known in human pathology, but other types of coronaviruses are specific to some species of birds and mammals, and may, under certain conditions, cross the species barrier, causing emerging human infections, as it happens with SARS-CoV-1, MERS CoV and SARS-CoV-2 [2].

Coronaviruses have genome stranded RNA, structured in reading regions of the genes encoding the replicase, the proteins are structural and nonstructural proteins (accessories). The structural proteinels are surface protein $S$ (spike protein), matrix protein $M$, and envelope $E$ protein $S$ can be cleaved by furin-like protease of the two subunits, S1 and S2 (Figure 1). The virus also contains an enzyme called replicase, that is expressing two polyproteins; $\mathrm{p} 1$ and $\mathrm{p} 1 \mathrm{ab}$, comprising more than 16 non-structural proteins $[3,4]$.

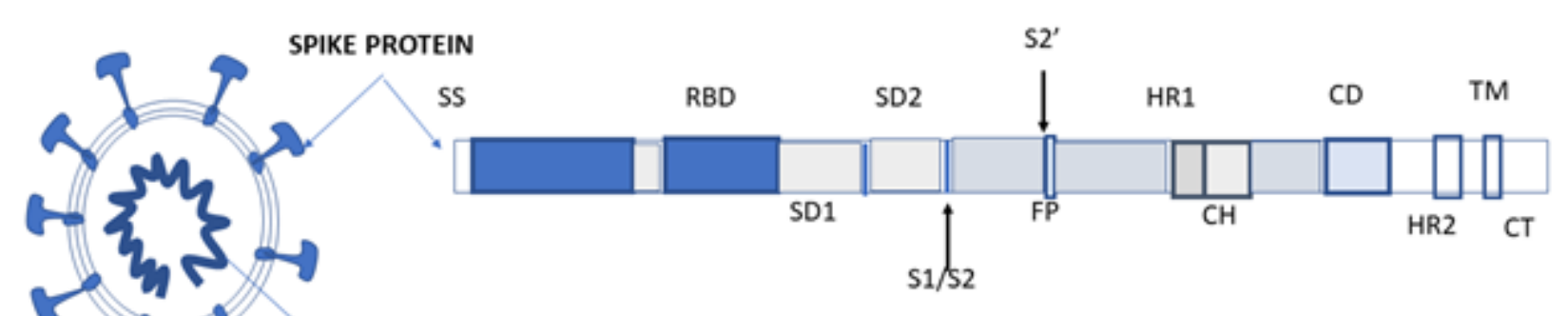

STRUCTURALDOMAINS OF SPIKE PROTEIN

SARS-CoV-2

Figure 1. The structure of SARS-CoV-2 and structural domains of spike (S) protein

Legend: CD—connector domain; $\mathrm{CH}$ — central helix; CT—cytoplasmic tail; FP—fusion peptide; HR1 and HR2—heptad repeats 1 and 2; SS — signal sequence, RBD — receptor binding domain, RBD subdomains 1 and 2-SD1 and SD2; S1/S2 - the protease cleavage site; S2' - the protease restriction site; TM-transmembrane domain.

Adapted on: WRAPP, D.; WANG, N.; CORBETT, K.S.; GOLDSMITH, J.A.; HSIEH, C.L.; ABIONA, O.; GRAHAM, B.S.;

MCLELLAN, J.S. Cryo-EM structure of the 2019-nCoV spike in the prefusion conformation. Science 367, 2020, $1260-1263$.

Viral replication cycle of coronavirus is initiated by the attachment of S protein on the surface of the virus to the host cell receptors. Further on, the proteolytic cleavage of the tick protein $S$ to produce the fusion of the virus with the host cell membrane $S$ and the formation of the endosome, which triggers the release of viral RNA in cytosol. In the cytosol of the host cell, nonstructural proteins were combined in the replication - transcription complex and produce an antisense genome, which contains the new viral genome RNA and subgenomic used as a RNM. The genome RNA, with the nucleocapsid, are attached to the intermediate portion of the endoplasmic reticulum Golgi, where synthetize in viral particles. These particles are assembled into new virions that are transported to the surface of the cell in vesicles and released outside through the exocytic fructose [3].

The SARS-CoV-2 sequencing allowed the identification of candidates for vaccines, most of them based on the genetic sequencing of the $S$ protein.

\section{Current knowledge about coronaviral vaccines}

Experience in influenza vaccination has proven that it took at least six months to use vaccine H1N1, during the pandemic of 2009, while that was necessare only an adaptation of vaccines known 
for new strains LA [5].

In coronaviruses case, we are facing some emerging viruses still unknown, the development of vaccines is more complex, must "take it from scratch" and therefore requiring a longer time.

Technologies for achieving vaccins evolved in recent years through the use of viral vectors or recombinant proteins or culture of the cell. Studies on vaccines anti SARS-CoV-1 and MERS showed that the viral surface protein $\mathrm{S}$, is an ideal target for the vaccin. In cases of SARS-CoV-1 SARS$C o V$, antibodies anti- protein $S$ interfere with the binding of viruses receptor ACE2, with its role to neutraltze [3].

Between vaccines anti-SARS-CoV-1 testated on animal models are known formula based on protein $S$ recombinant attenuated or inactivated and vector-based vaccine. The number of animals tested vaccines, although they made a protection against virus, haven't induced a sustainable immunity.

Animal studies have shown that the appearance of antibodies after the administration of a vaccine does not always protect against the disease. Moreover, the most vulnerable, who are at risk to make severe infection with $S A R S-C o V-2$, are the elderly, whose immunosenescence may be associated with a poor response to the vaccine. Other risk factors for lower efficiency of the vaccine, bind and immune response, may be obesity, mal nutrition, chronic infections and other causes of immunosuppression.

Live vaccines used in animal models have often produced complications such as lung lesions with eosinophilic infiltrates or liver damage. However, the vaccine was associated with survival and it may increase the level of viral, lower than the non-vaccinated animals [6].

Studies on vaccines SARS-CoV-1 and going in different animal models have brought attention to a new concern, related to the phenomenon of " antigen-dependent enhancement" (ADE), which refers to the increase in the entry of the virus into the host cells intensification of the infectivity of the virus, determined by the presence of non-neutralizing antibodies, in case of natural exposure after vaccination [7].

Vaccinus anti- SARS COV-1 were limited to phase I trials and are not available for usage, while the anti vaccines MERS - CoV is located in the stages of pre-clinical and clinical studies.

All this shows that it is necessary to achieve an effective and safe vaccine for $S A R S-C o V-2$ we have to travel a long way, that the network takes time, estimated at least 6-18 months.

\section{The actual stage of the development of the vaccine COVID-19}

The research work to develop a vaccine COVID-19 was started with the identification with area viral SARS-CoV genome-2, published in early January 2020. The humanitarian and economic impact of COVID 19 pandemy stimulated the commitment of a large number of pharmaceutical companies and biotechnology to share resources and, in the platforms technology to enable single accelerating the process of developing a vaccine (Table 1 ).

Table 1 Comparative duration of the clinical trials for classical vaccines and COVID 19 vaccine [8]

\begin{tabular}{|l|l|l|}
\hline Stages of the clinical trials & Classical vaccine & COVID-19 vaccine \\
\hline Preclinical stage & $18-30$ months & 0 months \\
\hline Clinical Phase I (drozens volunteers) & $\sim 30$ months & $\sim 6$ months \\
\hline Clinical Phase II (hundreds of volunteers) & $\sim 32$ months & $\sim 6$ months \\
\hline Clinical Phase III (thousands of volunteers) & $\sim 30$ months & $\sim 0$ months \\
\hline Aproval, Manufacture, Vaccination & $12-24$ months & $\sim 6$ months \\
\hline
\end{tabular}

Adapted on: Calina, D., Docea, A.O., Petrakis, D., Egorov, A.M., Ishmukhametov, A.A., Gabibov, A.G. ... Tsatsakis, A. (2020). Towards effective COVID-19 vaccines: Updates, perspectives and challenges(Review). International Journal of Molecular Medicine, 46, 3-16. https://doi.org/10.3892/ijmm.2020.4596 
Until April 8, 2020, there were registered 115 candidate vaccines, of which 78 were confirmed as active and 73 were under investigation or in preclinical studies [9]. These vaccines using a variety of impressive technologies, which include the use of nucleic acids (RNA or DNA), virus-like particles, peptides, viral vectors, protein is recombinant, live viruses attenuate or inactivated [10] (Table 2).

Table 2. Types of vaccins in development that has triggered immune response anti-COVID-19

\begin{tabular}{|c|c|c|}
\hline Vaccine categories & Vaccine types & Characteristics \\
\hline \multirow[t]{2}{*}{ Virus vaccines } & Inactivated & \multirow{2}{*}{$\begin{array}{c}\text { Inject the target virus directly, after inactivation/attenuation of pathogenicity. } \\
\text { Viral attenuation is obtaining by passage thorough animal or human cells; } \\
\text { Viral inactivation use formaldehyde or heat }\end{array}$} \\
\hline & Live- attenuated & \\
\hline \multirow[t]{2}{*}{ Viral-vector vaccines } & Replicating & \multirow{2}{*}{$\begin{array}{l}\text { Use a different virus genetically engineered to produce the proteins of the target virus } \\
\text { Replicating viral vector (such as vaccinal measles strain) induce strong immune } \\
\text { response } \\
\text { Non-replicating viral vector (such as adenovirus) need booster shots to induce long- } \\
\text { time immunity }\end{array}$} \\
\hline & Non-replicating & \\
\hline \multirow[t]{2}{*}{ Nucleic-acid vaccines } & RNA & \multirow{2}{*}{$\begin{array}{c}\text { Inject DNA or RNA of the target virus into cells to generate specific proteins } \\
\text { RNA is often coated in a lipid coat to enter cells } \\
\text { Most of these vaccines encode the virus spike (S) protein. } \\
\text { Are safe and easy to develop because envolve only the genetic material, not all the } \\
\text { virus }\end{array}$} \\
\hline & $\overline{\text { DNA }}$ & \\
\hline $\begin{array}{l}\text { Protein-based } \\
\text { vaccines }\end{array}$ & Protein subunit & $\begin{array}{l}\text { Inject protein subunits of the target virus directly into the body. } \\
\text { This vaccines require adjuvants and multiple doses }\end{array}$ \\
\hline Virus-like particles & & $\begin{array}{c}\text { Non-infectious and safe because of the chimeric structure, with empty virus but lack } \\
\text { of genetic material } \\
\text { Induce a strong immune response }\end{array}$ \\
\hline
\end{tabular}

Adapted on: Chen, W., Strych, U., Hotez, P.J. et al. The SARS-CoV-2 Vaccine Pipeline: an Overview. Curr Trop Med Rep 7, 61-64 (2020). https://doi.org/10.1007/s40475-020-00201-6

Thus, the first vaccine entered the clinical trials phase in March 2020, with unprecedented rapidity. This is called mRNA-1273, using an experimental technology, which has not yet been approved complicated for any other disease, although some studies have reached the second phase of testing it. The vaccine mRNA-1273 is based on the ability of molecules RNA to "teach" the cells to produce a specific antigen, educate then IMU system in to respond appropriately to the factual virus [8].

The following vaccine is $\mathrm{Ad} 5-\mathrm{nCoV}$, realised by genetic engineering. The principle of this vaccine is to teach the immune system to recognize coronaviral $\mathrm{S}$ protein, administered complicated by adenovirus type 5, often used for genetic recombination [11].

Although clinically studies started with these vaccines, followed soon other candidates, but passing to phase II is possibile in some months.

Limits are accorded for efficiency and safety identified other anticoronaviral vaccins that must be considered and as SARS vaccine-CoV-2. To all this, add insufficient knowledge about the purity and safety of vaccine adjuvants. Nowadays, vaccines anti- SARS-CoV-2 are based on the rules for "orphan drugs" and international regulations on being vaccines in pandemic conditions, which means that the lack of safety tests on long term, may influence of the efficiency of the vaccine may in some flaws of design, omission of signaling reactions second network or negligence in the test.

\section{Conclusions}

The development of anti-COVID-19 vaccines has been driven by the decipherment of the structure of the SARS -CoV-2 virus and the viral genome. Experience vaccines SARS-CoV-1 and -MERS-CoV may be useful to concepe vaccine for emerging virus of SARS-CoV-2. Developing a vaccine antiCOVID-19 efficient, safe and accessible in the shortest possible time, stays the biggest challenge overall in the race to limit pandemic today. 


\section{References}

1.CHEN, N., ZHOU, M., DONG, X., QU, J., GONG, F., HAN, Y., QIU, Y., WANG, J., LIU, Y., WEI, Y., et al. Epidemiological and clinical characteristics of 99

cases of 2019 novel coronavirus pneumonia in Wuhan, China: a descriptive study. Lancet, 395, 2020, 507-513.

2.CUI, J., LI, F., AND SHI, Z.L. Origin and evolution of pathogenic coronaviruses. Nat. Rev. Microbiol, 17, 2019, 181-192.

3.AMANAT, F., AND KRAMMER, F. SARS-CoV-2 Vaccines: Status Report. Immunity. 52, 2020, 583-589. https://doi.org/10.1016/j.immuni.2020.03.007

4.FEHR, A.R. AND PERLMAN, S. Coronaviruses: an overview of their replication and pathogenesis. Methods Mol. Biol, 1282, 2015, 1-23.

5.KRAMMER, F. AND PALESE, P. Advances in the development of influenza virus vaccines. Nat. Rev. Drug Discov, 14, 2015,167-182.

6.AGRAWAL, A.S., TAO, X., ALGAISSI, A., GARRON, T., NARAYANAN, K., PENG, B.H., COUCH, R.B., AND TSENG, C.T. Immunization with inactivated Middle East Respiratory Syndrome coronavirus vaccine leads to lung immunopathology on challenge with live virus. Hum. Vaccin. Immunother, 12, 2016, 2351-2356.

7.PADRON-REGALDO, E.. Vaccines for SARS-CoV-2: Lessons from Other Coronavirus Strains. Infect Dis Ther, 9, 2020,255-274. https://doi.org/10.1007/s40121-020-00300-x

8.CALINA, D., DOCEA, A.O., PETRAKIS, D., EGOROV, A.M., ISHMUKHAMETOV, A.A., GABIBOV, A.G. ... TSATSAKIS, A. Towards effective COVID-19 vaccines: Updates, perspectives and challenges (Review). International Journal of Molecular Medicine, 46, 2020, 3-16. https://doi.org/10.3892/ijmm.2020.4596

9.LE, T.T, ANDREADAKIS Z., KUMAR, A., ROMAN, R.G., TOLLEFSEN, S., SAVILLE, M., MAYHEW, S. The COVID-19 vaccine development landscape. Nature Reviews, 19, 2020,305-306. https://doi.org/10.1038/d41573-020-00073-5.

10.CALLAWAY, E. The race for coronavirus vaccines: a graphical guide. Nature. 580(7805), 2020, 576-577. doi:10.1038/d41586-020-01221-y.

11.ZHOU, F.C., LI, Y.H., GUAN, X.H., HOU, L.H., WANG, W.J., LI, J.X., ET AL. Safety, tolerability and immunogenicity of a recombinant adenovirus type 5 vectored COVID-19 vaccine: a dose-escaladation, open-label, non-randomised, first-in-human trial. Lancet, 395(10240), 2020,18451854 DOI: https://doi.org/10.1016/S0140-6736(20)31208-32.

12. WRAPP, D.; WANG, N.; CORBETT, K.S.; GOLDSMITH, J.A.; HSIEH, C.L.; ABIONA, O.; GRAHAM, B.S.; MCLELLAN, J.S. Cryo-EM structure of the 2019-nCoV spike in the prefusion conformation. Science 367, 2020, 1260-1263.

Manuscript received: 19.06 .2020 